\section{Promoção da saúde em famílias com paramiloidose: papéis dos mais velhos junto dos mais novos}

\author{
Health promotion in families with paramyloidosis: \\ the role of elders with younger family members
}

Promoción de la salud en familias con paramiloidosis:
papeles de los más viejos junto a los más jóvenes
Carla Roma Oliveira 1,2

Álvaro Mendes 3,4

Liliana Sousa 2

\section{Resumo}

Atualmente os cidadãos são parceiros dos sistemas formais na promoção da saúde. Na gestão das doenças hereditárias, o papel dos familiares como fonte de suporte é vital. O papel dos mais velhos emerge como crucial pela longa relação com a doença e com os doentes na família. Contudo, esse papel permanece pouco explorado, em particular, em doenças genéticas, como a paramiloidose. Este estudo qualitativo exploratório analisa o papel dos mais velhos, em famílias com paramiloidose, na promoção da saúde dos mais novos. Adotou-se a técnica dos incidentes críticos, aplicada por entrevista semiestruturada. $O$ estudo envolve 18 participantes que relataram 76 incidentes críticos. As entrevistas foram gravadas e submetidas a análise de conteúdo. Os principais resultados sugerem os seguintes papéis dos mais velhos junto dos mais novos: modelar (comportamentos), encorajar, informar e apoiar. As gerações mais velhas podem ser envolvidas pelos profissionais de saúde como parceiras no apoio aos mais novos em famílias com paramiloidose.

Promoção da Saúde; Doenças Genéticas Inatas; Amiloidose Familiar;

Relações Familiares

\author{
Correspondência \\ C. R. Oliveira \\ Associação dos Lares Ferroviários. \\ Rua dos Ferroviários 22, Entroncamento 2330-144, Portugal. \\ carlaromaoliveira@ua.pt \\ 1 Associação dos Lares Ferroviários, Entroncamento, Portugal. \\ 2 Universidade de Aveiro, Aveiro, Portugal. \\ 3 i3S Instituto de Investigação e Inovação em Saúde, UnIGENe, \\ Porto, Portugal. \\ 4 Instituto de Biologia Molecular e Celular, Universidade do \\ Porto, Porto, Portugal.
}




\section{Introdução}

Atualmente espera-se que os cidadãos sejam parceiros dos sistemas formais na promoção da saúde 1,2 . Isso decorre da mudança do perfil epidemiológico das doenças, com a redução de doenças agudas e aumento de doenças crônicas. Nesse contexto, o paradigma de cuidados altera-se: o foco passa da doença e cura para a qualidade de vida dos indivíduos e promoção de saúde ${ }^{3}$. Essa mudança implica um papel mais ativo do indivíduo doente, da sua família e, em geral, dos cidadãos 3,4. As doenças hereditárias não se circunscrevem ao indivíduo, pois outros familiares podem também ser afetados devido à transmissão hereditária 5,6,7. Assim, as doenças hereditárias são doenças da família, e a gestão dos comportamentos de saúde em indivíduos afetados ou em risco de doenças genéticas envolve toda a família. A literatura tem sugerido a importância dos elementos mais velhos no contexto familiar, em particular quando existem doenças crônicas severas, principalmente hereditárias 7,8. Esse papel tem sido abordado sobretudo no âmbito dos cânceres hereditários, mas permanece pouco explorado, principalmente como recurso para os mais novos. Os estudos indicam o envolvimento de elementos mais velhos no encorajamento à realização de rastreamentos e a sua associação a níveis mais elevados de intenção de adesão 9 . Os mais velhos surgem ainda como fonte de segurança e aconselhamento, dando informação sobre saúde, apoio e influência social, especialmente junto dos mais jovens 10. A literatura evidencia também a sua importância na eficaz disseminação da história de saúde na rede familiar 7,9,11. O acesso à história médica da família é importante na avaliação do risco genético individual. Os familiares mais velhos têm sido descritos como "guardiões da história médica da família" pelo conhecimento privilegiado de circunstâncias de saúde de antepassados aos quais não é possível aceder (porque já morreram ou estão muito incapacitados) 12 .

Contudo, não se conhecem estudos neste tópico, no âmbito da paramiloidose, uma doença hereditária de início tardio, que se manifesta na idade adulta (por norma, antes dos 40 anos) 13. Essa doença foi descrita pela primeira vez em 195214 e tem o foco de maior prevalência em Portugal, na zona costeira do norte do país. Carateriza-se por uma polineuropatia crônica progressiva de predomínio sensitivo e distal, simétrica, com início invariavelmente nos membros inferiores e com progressão ascendente 15. Para além da perda de sensibilidade térmica e álgica nos membros inferiores, surgem associadas doenças cardiovasculares, gastrointestinais, geniturinárias, oculares, renais e cutâneas 15 . $\mathrm{Na}$ fase final, os doentes ficam acamados, apresentando um déficit sensitivo-motor maior e alterações autonômicas, progredindo para a caquexia e morte em 10 a 15 anos após o início dos sintomas 15 . É uma doença monogênica para a qual existem testes pré-sintomáticos (TPS) desde 198516 que predizem se pessoas assintomáticas, em famílias com histórico de paramiloidose, são portadoras da mutação patogênica e virão a manifestar a doença no futuro. Atualmente a doença é incurável, e as opções de tratamento disponíveis (transplante hepático, desde 1992, ou medicação, desde 2012) apenas retardam a sua evolução 13. O TPS é um processo complexo com implicações psicossociais a nível individual e familiar 17,18. No caso da paramiloidose, os indivíduos são confrontados com um conjunto de decisões e ações na promoção e gestão da sua saúde: quando realizar o TPS e saber o resultado, e como gerir a comunicação da informação genética na família e na rede social pessoal. O diagnóstico genético precoce é relevante em termos clínicos na detecção inicial dos sintomas, o que irá maximizar a eficácia dos tratamentos disponíveis e a qualidade de vida 19,20. O diagnóstico precoce pode ainda ser relevante na tomada de decisões sobre opções de tratamento e planeamento reprodutivo 21,22,23.

O objetivo deste estudo exploratório é analisar o papel dos mais velhos (incluindo portadores e não portadores) junto dos mais novos, em termos de comportamentos de promoção da saúde e gestão do risco genético em famílias com paramiloidose. Os resultados darão subsídios para intervenções de promoção da autogestão individual e familiar do risco de doenças hereditárias, principalmente envolvendo a família.

\section{Metodologia}

Este estudo qualitativo e exploratório recorre à técnica dos incidentes críticos (TIC), por constituir um método que possibilita a coleta de eventos (acontecimentos) vividos pelos participantes que informaram o seu futuro, traduzindo e permitindo aceder à perspectiva individual de comportamentos 
e papéis significativos 24,25 . Um incidente corresponde à atividade humana observável, que permite inferir sobre o sujeito e a sua ação; envolve a descrição de como alguém agiu, respondeu, sentiu e/ou pensou sobre o evento. Um incidente é crítico, pois a intenção da ação tem determinado significado para o narrador ${ }^{24}$. Os incidentes críticos permitem capturar as perspetivas pessoais de experiências significativas, refletindo contextos de relações interpessoais. Trata-se de uma metodologia que permite recolher eventos que ocorreram junto de especialistas (aqueles que vivem as situações), de forma a aprofundar conhecimento 26 . Em saúde, a TIC tem sido usada para estudar a relação entre profissionais de saúde e utentes 27; conhecer as vivências de familiares, por exemplo, de crianças hospitalizadas 28; identificar alterações no relacionamento familiar, por exemplo após a ocorrência de AVC 29; e para estudar relações familiares, designadamente a transmissão intergeracional de informação ginecológica 30.

\section{Instrumento}

A TIC foi aplicada por meio de entrevistas telefônicas, com base em um questionário semiestruturado. A entrevista iniciou-se com o seguinte convite:

"Pense num ou mais acontecimentos que envolvam uma pessoa da geração mais velha da sua família que tenha sido marcante na forma como encara a paramiloidose na sua vida, na vida da sua família elou que tenha influenciado a forma como gere a doença e impactos associados. Por favor, pense numa situação da qual se lembre com clareza e que tenha sido realmente significativa para si (tenha ficado gravada na sua memória)".

A entrevista continuou com questões de desenvolvimento do tópico inicial: descrição detalhada da situação; quem estava presente; o que mais o/a impressionou; local onde ocorreu; como se sentiu; como classifica o impacto desse acontecimento, em si, na sua família, por quê. No final, coletaram-se os seguintes dados: (i) sociodemográficos dos participantes e dos elementos da geração mais velha protagonistas do incidente crítico (idade, sexo e escolaridade); (ii) estatuto perante o risco/doença do participante e do protagonista (não portador; portador pré-sintomático; portador sintomático, considerando tipo de tratamento: transplantado; medicação; sem tratamento).

\section{Procedimentos}

Este estudo obteve aprovação da Comissão de Ética Humana do Instituto de Biologia Molecular e Celular da Universidade do Porto, Porto, Portugal. Os participantes no estudo foram selecionados de forma intencional e não probabilística. O recrutamento foi mediado pela Associação Portuguesa de Paramiloidose (APP). A APP foi contactada e uma reunião foi marcada para a apresentação do projeto e a indicação da colaboração solicitada. Nessa reunião, a APP aceitou colaborar por meio da divulgação do projeto junto dos associados e mediar contatos entre potenciais participantes e investigadores. Foram indicados os critérios de inclusão dos participantes: membros de famílias com histórico de paramiloidose; idade $\geq 18$ anos; orientados no tempo e espaço; portadores e não portadores, pois a literatura sugere a influência de ambos. E foram referidos os critérios de exclusão: ter diagnóstico psiquiátrico; abusar de substâncias; estar em situação clínica crítica. Esses critérios foram adotados para excluir participantes com capacidade diminuída na compreensão do estudo e/ou a viverem situações em que potencialmente a participação no estudo pudesse trazer sofrimento adicional. Os critérios de inclusão/exclusão foram garantidos no contato com a APP e, posteriormente, pelo juízo clínico da entrevistadora (C.R.O., psicóloga).

Assim, aos interessados em colaborar no estudo, a APP disponibilizava um contato de correio eletrônico ou telefone dos investigadores; ou era enviado pela APP o contato do interessado aos investigadores. Esse procedimento foi completado pelo processo de bola de neve para recrutar mais participantes (pedir a cada participante que identificasse outro/s potencial/is participante/s e mediasse o contato). O primeiro contato com os potenciais participantes ocorreu por via telefônica, em que o investigador (C.R.O.) explicava objetivos, metodologia e colaboração solicitada. Todos aceitaram colaborar e foi agendada a entrevista (hora e data) de acordo com a conveniência dos participantes. Foi ainda obtido o consentimento informado verbal, registado por meio de gravação de áudio, que incluía autorização de gravação da entrevista. A duração média das entrevistas foi de 25 minutos (mínimo = 10 minutos; máximo $=49$ minutos). $\mathrm{O}$ recrutamento terminou com 18 participantes (76 incidentes 
críticos relatados), quando os autores concordaram que o ponto de saturação (situação em que os dados já foram ouvidos durante a coleta) tinha sido atingido 31. Utilizou-se a avaliação inter-juízes para determinar a saturação: a primeira autora que conduziu as entrevistas anunciou quando considerou ter sido atingida a saturação; os dois outros autores leram independentemente os incidentes críticos e indicaram a sua concordância.

\section{Participantes}

Este estudo envolve 18 participantes, com idades entre os 18 e 65 anos (média etária $=42$ anos). Em termos de grupo etário: $\leq 20$ anos $=1 ; 21-30$ anos = 2; 31-40 anos = 3; 41-50 anos = 9; 51-60 anos = $2 ; \geq 61$ anos $=1$. Dez são do sexo feminino. Quanto à escolaridade: até quatro anos de escolaridade $=$ 1 participante; de cinco a nove anos de escolaridade $=10 ; 12^{\circ}$ ano $=4$; Ensino Superior $=2$ ( 1 participante não responde). Em relação à condição perante a doença, verifica-se que 11 são portadores sintomáticos ( 8 foram transplantados e 3 tomam medicação), 2 são portadores assintomáticos, 4 são não portadores e 1 ainda não sabe (não realizou teste genético).

\section{Análise de dados}

As entrevistas foram gravadas, ouvidas na totalidade e os incidentes críticos transcritos e submetidos a análise de conteúdo ${ }^{32}$, por dois juízes independentes (primeiro e terceiro autores). Os juízes começaram por ler todos os 78 incidentes críticos para decidir os usáveis. Nesse processo, foram eliminados dois incidentes críticos que não estavam relacionados com os objetivos do estudo; por exemplo, não relatavam uma ação de uma pessoa da geração mais velha junto da mais nova. Em seguida, procedeu-se à criação e à testagem do sistema de categorização. Cada juiz leu os incidentes críticos e desenvolveu uma lista de (sub)categorias relativas aos papéis dos mais velhos junto dos mais novos. Depois reuniram-se para comparar e discutir as propostas. Esse processo repetiu-se até chegarem a acordo. Em seguida, cada juiz categorizou aleatoriamente cinco incidentes críticos de forma a confirmar a adequação do sistema de categorização; o sistema revelou-se adequado (Tabela 1). Em seguida, os dois juízes categorizaram de forma independente cada incidente crítico. Em seguida, reuniram-se para analisar as concordâncias e as discordâncias; a concordância entre juízes (valor calculado pela divisão de número de concordâncias pelo total de concordâncias e discordâncias) foi de 81,6\%, o que indica boa fiabilidade 32 . Por fim, discutiram as discordâncias, e esse processo conduziu à concordância em todos os incidentes críticos.

\section{Resultados}

Foram relatados 76 incidentes críticos por 18 participantes (Tabela 1). Três participantes relataram um incidente (mínimo) e dois relataram 10 (máximo), uma média de 4,3 incidentes por participante.

\section{Modelar comportamentos perante a doença}

Esta categoria representa 52,6\% dos incidentes críticos relatados. Refere-se a eventos em que os mais velhos não têm uma intenção específica, mas pelo seu comportamento influenciam os mais novos. Envolve três subcategorias: "normalizar" (25\%) versus "dramatizar a vivência da doença” (5,3\%), em que se transmitem formas de enfrentar a doença; e "ser testemunho vivo da doença" $(22,4 \%)$, em que os mais novos assistem à progressão dos sintomas nos mais velhos portadores. Os mais velhos "normalizam a vivência da doença” quando continuam a cuidar apesar da visibilidade dos sintomas; ou dão apoio e se preocupam com os outros, apesar de doentes; participam em estudos experimentais; e também quando os mais velhos não portadores cuidam dos mais velhos portadores, permitindo aos mais novos "terem uma vida".

"A minha mãe tem a doença mas parece que não tem. Na cabeça dela, o viver dela, a pessoa percebe que ela (...) tem mazelas, mas quem a ouvir a falar, ela não tem nada" (Mulher, portadora, 32 anos). 


\section{Tabela 1}

Categorias: papéis dos mais velhos junto dos mais novos em famílias com polineuropatia amiloidótica familiar (paramiloidose).

\begin{tabular}{|c|c|}
\hline Categorias/Sub-categorias & $\begin{array}{c}\text { Incidentes críticos }(\mathbf{N}=76) \\
\text { n (\%) }\end{array}$ \\
\hline Modelar comportamentos perante a doença & $40(52,6)$ \\
\hline Normalizar a vivência da doença & $19(25,0)$ \\
\hline Ser testemunho vivo da doença & $17(22,4)$ \\
\hline Dramatizar a vivência da doença & $4(5,3)$ \\
\hline (Não) informar sobre risco/doença & $15(19,7)$ \\
\hline Não falar (silenciar) & $6(7,9)$ \\
\hline Informar & $5(6,6)$ \\
\hline Incentivar a procura de informação & $4(5,3)$ \\
\hline (Des)encorajar realização do teste genético & $14(18,4)$ \\
\hline Encorajar & $6(7,9)$ \\
\hline Apoiar qualquer decisão & $3(3,9)$ \\
\hline Acompanhar na realização do teste & $3(3,9)$ \\
\hline Desencorajar & $2(2,6)$ \\
\hline Apoiar & $12(15,8)$ \\
\hline Apoiar emocionalmente perante resultado de portador & $4(5,3)$ \\
\hline Aconselhar sobre decisões da vida pessoal & $3(3,9)$ \\
\hline Apoiar emocional e instrumentalmente durante a doença & $3(3,9)$ \\
\hline Apoiar decisão de realizar tratamentos disponíveis & $2(2,6)$ \\
\hline
\end{tabular}

Alguns elementos mais velhos "dramatizam a vivência da doença"; entregam-se à doença, não querem sair de casa, manifestam desesperança; recusam-se ir ao médico, desejam a morte.

“A minha mãe dizia: 'Por que Deus não me leva?"' (Mulher, portadora, 42 anos).

Os mais velhos portadores doentes são "testemunhas vivas da doença”. Os mais novos veem através deles o que é viver com a doença: sofrimento (associados à doença e tratamentos), incapacidade progressiva, dependência e morte (por norma em uma idade "precoce"). Os mais novos afirmam que alguns sintomas afetam a "dignidade humana".

"Eu assisti à degradação diária da minha mãe durante 10 anos. Uma vez (...) ela se ajoelhou no chão do quarto para lavar o chão e ficou com as pernas em ferida, só do contato da pele com a madeira" (Mulher, portadora, 42 anos).

\section{(Não) informar sobre risco/doença}

Esta categoria (19,7\% dos incidentes críticos) relaciona-se com eventos em que os mais velhos transmitem e/ou incentivam a procura de informação sobre a doença e tratamentos. Envolve três subcategorias: "não falar (silenciar)" (7,9\%); "informar" (6,6\%) e "incentivar a procura de informações" (5,3\%). "Não falar (silenciar)" corresponde a eventos em que os mais velhos não falam sobre a doença, mesmo se questionados; os participantes consideram que esses familiares não "lidam bem" com a doença.

"Ela [mãe] foge às perguntas e a tudo, não fala! Quando começamos a falar, muda de assunto, nós já desistimos porque sabemos que não lida bem com isso" (Mulher, portadora, 26 anos).

Os mais velhos "informam" sobre diversos aspetos da doença: risco dos mais novos serem portadores (história na família, "lado" da família de onde parece provir); caraterísticas (sintomas) e mitos; transmitem informação recebida de profissionais de saúde e antepassados.

"Foi quando ela [mãe] me diz que nós, filhos, podíamos vir a ter aquela doença" (Homem, portador, 46 anos). 
A subcategoria "incentivar a procura de informações" corresponde a incidentes em que sobretudo os mais velhos não portadores acompanham os mais novos, por norma aqueles que ainda desconhecem o seu estatuto perante a doença (ainda não realizaram o teste genético), a congressos e/ou a visitar e falar com doentes para que conheçam diversas experiências.

"Lembro-me de uma vez, há uns 10 anos, que fui com ele [pai] a uma instituição onde estavam internados, $e$ acho que ainda estão, doentes em fase terminal; fui lá falar com alguns para ver que nem toda a gente encara a doença da mesma forma, uns aceitavam e outros não aceitavam” (Mulher, portadora, 26 anos).

\section{(Des)encorajar realização do teste genético}

Esta categoria $(18,4 \%)$ centra episódios em que os mais velhos influenciam os mais novos em relação à (não) realização do TPS. Inclui quatro subcategorias: "encorajar" (7,9\%); "apoiar qualquer decisão" (3,9\%); "acompanhar na realização do teste" (3,9\%); "desencorajar" (2,6\%). Alguns elementos mais velhos agem no sentido de "encorajar" os mais novos a realizar o TPS. Por norma, começam por falar sobre o assunto, sensibilizando e dando exemplos de outras pessoas doentes da família; alguns tendem a insistir e pressionar; outros optam por esperar que a pessoa mais nova esteja preparada.

"Vamos fazer as análises, para estarmos atentos, alerta" (Homem, portador, 50 anos).

A subcategoria "apoiar qualquer decisão" ocorre quando os mais novos têm a iniciativa, e os mais velhos apoiam qualquer decisão sobre a realização do teste (fazer, não fazer ou adiar).

"Elas [mãe e avó] estão passivas, é o que eu achar melhor; eu quero saber e elas apoiam-me; se eu não quisesse saber, também apoiavam" (Homem, desconhece estatuto perante a doença, 18 anos).

Os mais velhos "acompanham na realização do teste", incluindo as diversas diligências (como: marcar, acompanhar, receber diagnóstico e comunicar resultado).

"Lembro-me do dia em que chegaram os resultados, (...) lembro-me de quem estava presente, (...) estava a minha tia, (...) porque os resultados vieram para a médica de família, e a minha tia foi a primeira a saber e depois nós soubemos por ela" (Mulher, portadora, em sintomas, 42 anos).

Alguns membros da geração mais velha "desencorajam" os mais novos (principalmente filhos) a realizar o teste: não apoiam a decisão; fogem ou adiam falar sobre o assunto; e ignoram a procura de informação dos mais novos sobre a doença. Os mais novos consideram que os mais velhos têm medo de que o/s filho/s tenham a doença e/ou de como irão lidar com um resultado de portador (supõem que os mais novos não estão preparados).

"Ela [mãe] não queria que eu fizesse o teste. Para não sofrer aquilo que ela sofreu, aquele impacto" (Mulher, portadora, 31 anos).

\section{Apoiar}

Esta categoria $(15,8 \%)$ surge em eventos em que os portadores são membros mais novos da família, e inclui quatro subcategorias: "apoio emocional perante o resultado de portador" (5,3\%); "aconselhar sobre decisões de vida pessoal” (3,9\%); "apoio emocional e instrumental durante a doença” (3,9\%); "apoiar a decisão de realizar tratamentos disponíveis" (2,6\%). A subcategoria "apoio emocional perante o resultado de portador" corresponde a situações em que o resultado de portador aproxima emocionalmente elementos mais velhos e mais novos; os mais velhos aceitam o resultado e apoiam o mais novo, sobretudo dando esperança associada aos novos tratamentos.

"Nesse dia, quando cheguei a casa, depois de saber o resultado, estava [pai] à minha espera; abriu a porta e eu estava cabisbaixo, encharcado em lágrimas e ele agarrou-se e deu-me um abraço grande e disse 'já vi, também tu meu filho' (...); levantou-me a cabeça e deu-me um beijinho e disse 'filho, estamos juntos, vamos ultrapassar isto da melhor maneira"' (Homem, portador, 46 anos).

Os mais velhos, portadores ou não, "aconselham" os mais novos sobre decisões da vida pessoal, principalmente tendem a desaconselhar os portadores a ter filhos e os não portadores a casar com portadores.

"A minha madrinha [disse-me] no dia antes do casamento, que eu fui lá, 'pensa bem no que vais fazer" (Homem, não portador, 65 anos).

Os mais velhos, por norma não portadores, dão "apoio emocional e instrumental durante a doença” aos mais novos; isso inclui aspetos instrumentais (levar a consultas, comprar medicação, confeccionar refeições); e emocionais (manifestar preocupação, escutar). 
"Chamou o médico, e a ambulância veio e leva-o diretamente para as urgências. (...) Ela ficava preocupada com essas coisas” (Homem, portador, 49 anos).

Os mais velhos também "apoiam os mais novos a realizar os tratamentos disponíveis", pois significa lutar e não desistir. O transplante é o tratamento mais difícil de aceitar, porque envolve cirurgia e recuperação complexa. Os mais velhos, durante esse processo, dão apoio emocional e manifestam empatia.

"Quando fui transplantado, em 1994, (...) o meu pai (...) foi ver-me aos cuidados intensivos e (...) disse-me assim 'Ó filho, (...) quando a tua irmã for transplantada, já posso morrer descansado!” (Homem, não portador, 66 anos).

\section{Discussão}

As condições hereditárias alteram a vivência da doença, tradicionalmente individual, tornando-a familiar e intergeracional 33. Nesse contexto, os papéis e as relações familiares centradas na promoção da saúde são relevantes na adaptação ao risco genético e à doença.

Este estudo explorou o papel dos elementos mais velhos junto dos mais novos, em termos de comportamentos de promoção da saúde em famílias com paramiloidose. Os resultados sugerem diversos papéis: modelar (transmitir experiências no confronto e gestão da doença); informar (facilitar ou dificultar a passagem e acesso a informação sobre a doença); encorajar (incentivar ou desencorajar medidas de gestão do risco, detecção precoce e tratamento); e apoiar (recurso emocional e instrumental).

Esses papéis sugerem a influência dos mais velhos nas várias fases de adaptação familiar ao desenvolvimento da doença hereditária 33, considerando as pré-sintomáticas e sintomáticas. As pré-sintomáticas incluem: tomar consciência do risco genético familiar (início da comunicação familiar sobre doença e risco); crise I, pré-teste (ponderar e decidir sobre realizar o TPS); crise II, teste e pós-teste (realizar o TPS, aguardar e confrontar-se com o resultado); adaptação a longo prazo em indivíduos portadores (adaptar-se à condição; ser portador assintomático). As fases sintomáticas são: crise (início dos sintomas; tomada de decisão sobre tratamentos); crônica (compatibilizar a vida com a evolução da doença); terminal (pautada por tristeza, separação, morte, luto).

O papel "modelar" parece ser transversal às várias fases de evolução da doença (pré-sintomática e sintomática), sendo exercido por mais velhos portadores e não portadores, junto dos mais novos (independentemente do estatuto perante a doença: desconhecido, portadores e não portadores).

Como "testemunhos vivos da doença", os mais velhos portadores permitem aos mais novos, desde idades precoces e ao longo das suas vidas, observar o que é a doença (sintomas e evolução), como ser acometido pela enfermidade (vivência dos portadores sintomáticos) e como é viver com ela na família. Esse papel permite aos mais novos tomar consciência da doença e vai influenciar decisões de gestão da saúde (por exemplo, realizar ou não o TPS; fazer ou não tratamentos). O papel "modelar" envolve ainda as formas de enfrentar a doença (normalizar vs. dramatizar).

Os mais velhos portadores (modo como gerem e enfrentam a sua doença) e não portadores (forma como gerem e enfrentam a doença em elemento(s) significativo(s) da família) mostram aos mais novos (com diversos estatutos perante a doença) como normalizar a vivência da doença (por exemplo, compatibilizar a gestão da doença com funções familiares, sociais e profissionais) ou, com menos frequência, dramatizam (potenciando que os mais novos sejam absorvidos pelo medo e desespero).

Os papéis "(não) informar" e "(des)encorajar" parecem ocorrer em fases assintomáticas e de transição (ou momentos-chave) da evolução da doença, exercidos por mais velhos portadores e não portadores, junto de mais novos que desconhecem o estatuto perante a doença. (Não) informar é relevante na tomada de consciência da doença pelos mais novos que desconhecem o estatuto perante a doença, e parece influenciar a decisão de realização do TPS, relevante na detecção atempada dos sintomas e início dos tratamentos, e no planeamento reprodutivo.

A decisão dos mais velhos de informar e incentivar a procura de informação parece ser um apelo à realização do TPS; contudo, silenciar não assinala um desincentivo, parecendo ocorrer porque os mais velhos não sabem como gerir um resultado de portador nos mais novos (com frequência, filhos).

“(Des)encorajar” centra a decisão de realizar (ou não) o TPS, envolvendo familiares mais velhos, portadores e não portadores, junto dos mais novos que desconhecem o estatuto perante a doença. A 
realização do TPS envolve estresse psicossocial, pois vai definir o estatuto individual perante a doença e poderá indicar outros elementos da família em risco 17,21,23. Em geral, os mais velhos encorajam a realização do TPS, e até acompanham e ajudam nos contatos e marcações de consultas. No entanto, alguns optam por apoiar qualquer decisão dos mais novos, talvez porque assumem ser algo complexo que deve ser deixado à consideração individual. E outros desencorajam, provavelmente em uma tentativa de evitar o confronto com uma possível notícia de portador, para a qual sentem não estar preparados e/ou sentem que os mais novos não estarão.

O papel "apoiar" tende a ocorrer nas fases sintomáticas, sobretudo pelos mais velhos não portadores, junto dos mais novos portadores sintomáticos. Os mais velhos vão adaptando o seu papel de apoio às necessidades dos mais novos. Começam pelo apoio emocional, quando um elemento mais novo recebe resultado de portador da mutação (fase pré-sintomática). Em seguida, apoiar a decisão para realizar os tratamentos disponíveis, quando os primeiros sintomas ocorrem (fase sintomática: crise). Posteriormente, quando os mais novos experienciam a doença (fase sintomática: crônica), o apoio centra aspetos instrumentais (como transporte a consultas) e emocionais. O apoio também pode ocorrer na forma de aconselhamento sobre decisões da vida pessoal, essencialmente relacionado com o desejo de parar a doença (e.g. para que portadores não tenham filhos ou para que não portadores não se casem com alguém portador).

No estudo do papel dos mais velhos junto dos mais novos em famílias com história de doença genética, como a paramiloidose, é relevante uma leitura da dinâmica geracional, que pode incluir os desafios na interação entre mais velhos e mais novos no contexto da evolução das possibilidades da medicina genômica e sua influência no aconselhamento genético 34,35 .

Em uma família, convivem passados, presentes e futuros (antecipados), coexistindo gerações com experiências e identidades diferenciadas, que se sucedem no tempo, mas que partilham tempos 35,36,37. Atualmente, nas famílias com paramiloidose, coexistem gerações com vivências diferentes da doença, a qual pode ser analisada a partir de momentos relevantes na evolução da história da enfermidade.

A paramiloidose foi descrita cientificamente em 1952; até aí as comunidades de maior prevalência da doença desenvolveram mitos sobre a sua origem e caraterização (incluindo o contágio), que implicavam algum estigma social para essas famílias 38,39. Refira-se que os papéis de caráter negativo (dramatizar vivência da doença, não falar/silenciar, desencorajar) podem estar associados ao estigma em uma perspectiva intergeracional 40 .

O enfrentamento do estigma envolvia "esconder" a doença (não falando e evitando o tema); e quando tal se tornava inviável, por conta de os sintomas serem manifestos, era vivido como um drama difícil de ser aceito 40. Esta é uma circunstância que aponta para um encontro intergeracional de vivências da doença: os mais velhos viveram mais esse estigma, ainda o sentem e temem, e transmitem-no aos mais novos.

Em 1985, fica disponível o TPS, que altera diversas vivências familiares: até aí a incerteza sobre um elemento ter ou não a doença apenas se transformava em certeza com o surgimento dos sintomas. O TPS indica se as pessoas são ou não portadoras, permitindo-lhes viver sem sintomas, em muitos casos durante anos (o que representa um desafio à identidade: um portador não sintomático tem a doença, mas é saudável até os sintomas ocorrerem); e também passa a ser possível fazer o planejamento reprodutivo e evitar ter descendentes portadores. Os papéis neste estudo parecem incluir essa evolução, pois os mais velhos tendem a informar sobre a doença e encorajar o TPS, em uma tentativa de integrarem as potencialidades atuais da medicina preditiva e evitarem a incerteza do passado.

Em 1992, surge o primeiro tratamento (não curativo), o transplante hepático, que trouxe esperança e se revelou eficaz no abrandamento da progressão dos sintomas. Em 2012, surgiu novo tratamento não curativo, por via oral e menos agressivo. A disponibilidade desses tratamentos está incorporada nos papéis dos mais velhos, que informam sobre a doença e encorajam a realização do TPS, procurando certeza sobre a condição genética e potenciando o acesso a tratamentos mais eficazes (se iniciados aquando dos primeiros dos sintomas).

Considerando que a dinâmica geracional é o processo de ação de umas gerações sobre as outras em um determinado período, estamos perante avanços significativos em um espaço temporal curto, que parecem ter vindo a ser incorporados nos papéis dos mais velhos junto dos mais novos 41 .

É esperado, com constantes desenvolvimentos científicos, que surjam (a curto prazo) novas e mais eficazes respostas terapêuticas para a paramiloidose. Será relevante compreender como essas 
evoluções serão incorporadas pelas várias gerações das famílias, e como serão refletidas nos papéis desempenhados pelos mais velhos 35 .

Os papéis poderão manter-se, embora veiculando conteúdos diferentes; por exemplo, transmitindo outros modelos de vivência da doença e tratamentos (menos sofrimento extremo; viver mais anos sem sintomas; menos mortes precoces), usando outros recursos de informação (maior acesso, menos estigma) e, eventualmente, diferentes necessidades e outras formas de apoiar. Entretanto, também podemos vir a assistir à emergência de outros papéis.

As diversas gerações em famílias com histórico de paramiloidose viveram, vivem e vão viver tempos diferentes em termos de informação sobre a doença, exposição mais prolongada à informação preditiva e novas possibilidades de tratamento. Essa evolução moldará a vivência da doença para as diferentes gerações e necessita de ser acompanhada pelos serviços e profissionais de saúde.

\section{Implicações}

Em um contexto em que os avanços tecnocientíficos da genômica permitem desenvolver testes genéticos cada vez mais refinados na detecção e cálculo de riscos associados a um número crescente de doenças genéticas raras e comuns, a investigação dos meios informais de adaptação psicossocial em famílias afetadas é fundamental para promover cuidados de saúde e potenciar políticas de saúde eticamente responsáveis.

A paramiloidose, uma doença monogênica para a qual existem TPS e tratamentos não curativos, poderá constituir um exemplo no estudo da adaptação biopsicossocial na era genômica. Ademais, pode informar a análise das relações intergeracionais em doenças hereditárias. Os profissionais de saúde deverão estar atentos à diversidade com que os papéis são assumidos, à evolução do conhecimento sobre a doença e à necessidade de ajustar formas de gerí-la. Poderão apresentar alternativas e incentivar familiares mais velhos facilitadores a participarem na intervenção, contribuindo para que os mais novos possam tomar as próprias decisões.

\section{Limites e perspectivas de pesquisa}

A principal limitação deste estudo é o número reduzido de participantes (18), apesar da saturação de dados (76 incidentes críticos). Além disso, os participantes são principalmente pessoas da geração intermédia (31-52 anos). Um maior número de participantes que incluísse mais pessoas da geração mais idosa e da mais nova permitiria compreender melhor os papéis, as relações de parentesco e a incorporação da evolução da medicina preditiva.

A perspetiva intergeracional necessita de aprofundamento em futuros estudos, designadamente para compreender se os papéis dos mais velhos junto dos mais novos são específicos, ou também desempenhados por outros familiares. Estudos futuros poderiam incluir a perspetiva de elementos da família que se recusaram a fazer o teste genético; analisar a evolução nos papéis dos mais velhos à medida que surgem novos tratamentos mais eficazes; recolher a visão dos profissionais e comparar perspectivas; e estudar o papel dos mais velhos no âmbito de outras doenças hereditárias.

\section{Conclusão}

Este estudo exploratório sugere quatro papéis dos mais velhos junto dos mais novos em famílias com paramiloidose: modelar, informar, encorajar e apoiar. O envolvimento dos mais velhos em estratégias de promoção de saúde em doenças hereditárias enquadra-se na mudança dos paradigmas de saúde que sugerem maior partilha de responsabilidade pelos cuidados entre cidadãos/familiares e profissionais de saúde. $\mathrm{O}$ envolvimento dos mais velhos na gestão familiar do risco genético pode contribuir para a eficácia da disseminação de medidas preventivas de vigilância e comportamentos mais saudáveis nos elementos da família. Os resultados deste estudo têm implicações na análise das relações intergeracionais em outras doenças hereditárias. 


\section{Colaboradores}

C. R. Oliveira, A. Mendes e L. Sousa participaram na concepção geral do estudo; análise e interpretação dos dados; redação e revisão crítica do conteúdo; aprovação da versão final a ser publicada.

\section{Agradecimentos}

Os autores agradecem a colaboração prestada pela Associação Portuguesa de Paramiloidose, e a todos os participantes pela partilha do seu tempo e experiência. A. Mendes é bolsista de pós-doutoramento da Fundação para a Ciência e Tecnologia (SFRH/ $\mathrm{BPD} / 88647 / 2012$ ).

\section{Referências}

1. Crisp N. Um futuro para a saúde. Lisboa: Fundação Calouste Gulbenkian; 2014.

2. Ferreira MS, Castiel LD. Which empowerment, which health promotion? Conceptual convergences and divergences in preventive health practices. Cad Saúde Pública 2009; 25:68-76.

3. Souza EM, Grundy E. Promoção da saúde, epidemiologia social e capital social: inter-relações e perspectivas para a saúde pública. Cad Saúde Pública 2004 20:1354-60.

4. Taylor D, Bury M. Chronic illness, expert patients and care transition. Sociol Health Illn 2007; 29:27-45.

5. Rolland JS. Chronic illness and the life cycle. Fam Process 1987; 26:203-21.

6. Rolland JS. Mastering family challenges in serious illness and disability. In: Walsh F, editor. Normal family processes. 4th Ed. New York: Guilford Press; 2012. p. 452-82.

7. Mendes A. Doenças hereditárias, aconselhamento genético e redes familiares e sociais:da ética intergeracional ao papel dos mais velhos. Rev Kairós 2012; 15:199-216.

8. Ashida S, Schafer EJ. Family health information sharing among older adults: reaching more family members. J Community Genet 2015; 6:17-27.

9. Ashida S, Wilkinson AV, Koehly LM. Motivation for health screening. evaluation of social influence among Mexican-American adults. Am J Prev Med 2010; 38:396-402.

10. Ashida S, Hadley DW, Goergen AF, Skapinsky KF, Devlin HC, Koehly LM. The importance of older family members in providing social resources and promoting cancer screening in families with a hereditary cancer syndrome. Gerontologist 2011; 51:833-42.

11. Koehly LM, Peters JA, Kenen R, Hoskins LM, Ersig AL, Kuhn NR, et al. Characteristics of health information gatherers, disseminators, and blockers within families at risk of hereditary cancer: Implications for family health communication interventions. Am J Public Health 2009; 99:2203-9.

12. Mendes A, Sousa L. Families' experience of oncogenetic counselling: accounts from a heterogeneous hereditary population. Fam Cancer 2012; 11:291-306.

13. Adams D, Suhr OB, Hund E, Obici L, Tournev I, Campistol JM, et al. First European consensus for diagnosis, management, and treatment of transthyretin familial amyloid polyneuropathy. Curr Opin Neurol 2016; 29 Suppl 1: S14-26.

14. Andrade C. A peculiar form of peripheral neuropathy. Brain 1952; 75:408-27.

15. Conceição I. Clínica e história natural da polineuropatia amiloidotica familiar. Sinapse 2006; 6(1 Suppl 1):86-91.

16. Sequeiros J. O teste preditivo da doença de Machado-Joseph. Porto: Instituto De Biologia Molecular e Celular, Universidade do Porto; 1996. 
17. Lêdo S, Paneque M, Rocha J, Leite A, Sequeiros J. Predictive testing for two neurodegenerative disorders (FAP and HD): a psychological point of view. Open J Genet 2013; 3:270-9.

18. Lopes A. Aspetos psiquiátricos e psico-sociais nos doentes com PAF. Sinapse 2006; 6(1 Suppl 1): 129-33.

19. Zagalo-Cardoso AJ, Rolim L. Aspetos psicossociais da medicina preditiva: revisão da literatura sobre testes de riscos genéticos. Psicol Saúde Doenças 2005; 6:3-34.

20. Furtado E. Transplantação hepática na polineuropatia amiloidótica familiar. Sinapse 2006; 6(1 Suppl 1):151-4.

21. Paneque M, Lemos C, Sousa A, Velázquez L, Fleming M, Sequeiros J. Role of the disease in the psychological impact of pre-symptomatic testing for SCA2 and FAP ATTRV30M: experience with the disease, kinship and gender of the transmitting parent. J Genet Couns 2009; 18:483-93.

22. Valdrez K, Silva S, Coelho T, Alves E. Awareness and motives for use and non-use of preimplantation genetic diagnosis in familial amyloid polyneuropathy mutation carriers. Prenat Diagn 2014; 34:886-92.

23. Flemming M, Lopes A. Saber ou não saber: dinâmica e impasses psicológicos na doença genética. Revista Portuguesa de Psicossomática 2000; 2:33-40

24. Flanagan JC. The critical incident technique. Psychol Bull 1954; 51:327-58.

25. Morman MT, Whitely M. An exploratory analysis of critical incidents of closeness in the mother/son relationship. J Fam Commun 2012; 12:22-39.

26. Kemppainen JK. The critical incident technique and nursing care quality research. J Adv Nurs 2000; 32:1264-71.

27. Sousa L, Ribeiro AP. Prestar cuidados de enfermagem a pessoas idosas. Saúde Soc 2013; 22:866-77.

28. Andraus LMS, Munari DB, Faria RM, Souza ACS. Incidentes críticos segundo familiares de crianças hospitalizadas. Rev Enferm UERJ 2007; 15:574-9.

29. Marques S, Rodrigues RAP, Kusumota L. Cerebrovascular accident in the aged: changes in family relations. Rev Latinoam Enferm 2006; $14: 364-71$
30. Warren-Jeanpiere L, Miller KS, Warren AM. African-American women's retrospective perceptions of the intergenerational transfer of gynecological care information received from mothers. J Fam Commun 2010; 10:81-98.

31. Mason M. Sample size and saturation in $\mathrm{PhD}$ studies using qualitative interviews. Forum Qual Soc Res 2010; 11:8.

32. Miles MB, Huberman AM. Qualitative data analysis. Thousand Oaks: Sage Publications; 1984.

33. Rolland J, Williams J. Toward a biopsychosocial model for 21 st-century genetics. Fam Process 2005; 44:3-24.

34. Weller W. A atualidade do conceito de gerações de Karl Mannheim. Sociedade e Estado 2010; 25:205-24.

35. Mannheim K. El problema de las generaciones. Revista Española de Investigaciones Sociológicas 1993; 62:193-242.

36. Pinder W. Das problem der generation in der Kunstgeschichte Europas. Berlin: Frankfurter Verlagsanstalt; 1926.

37. Atkinson P, Featherstone K, Gregory M. Kinscapes, timescapes and genescapes: families living with genetic risk. Sociol Health Illn 2013; 35:1227-41.

38. Novais SAL, Mendes FRP. Representation of illness in Familial Amyloidotic Polyneuropathy Portuguese Association newspaper. Nurs Health Sci 2016; 18:85-90.

39. Leite A, Dinis MAP, Sequeiros J, Paúl C. Subjects at-risk for genetic diseases in Portugal: illness representations. J Genet Couns 2016; 25:79-89.

40. Rolim L, Leite A, Lêdo S, Paneque M, Sequeiros J, Fleming M. Psychological aspects of pre-symptomatic testing for Machado-Joseph disease and familial amyloid polyneuropathy type I. Clin Genet 2006; 69:297-305.

41. Attias-Donfut C, Benoit-Lapierre N. La dynamique des générations. Communications 1994; 59:5-13. 


\section{Abstract}

Citizens are now partners in the formal health promotion system. In the management of hereditary diseases, the role of family members is a vital source of support. Elders play a crucial role due to their long relationship with the disease and with patients in the family. However, this role has still been insufficiently explored, particularly in genetic disorders like paramyloidosis. This exploratory qualitative study analyzes the role of elders in families with paramyloidosis, in health promotion for younger members. The critical incidents technique was applied using a semi-structured interview. The study involved 18 participants who reported 76 critical incidents. The interviews were taped and submitted to content analysis. The principal results suggest the following roles for elders with younger family members: act as role models (in behaviors), encourage, inform, and support. The older generations can be mobilized by health professionals as partners to support younger generations in families with paramyloidosis.

Health Promotion; Inborn Genetic Diseases; Familial Amyloidosis; Family Relations

\section{Resumen}

Actualmente, los ciudadanos son agentes activos en los sistemas formales en la promoción de la salud. En la gestión de las enfermedades hereditarias, el papel de los familiares como fuente de apoyo es vital. El papel de los más viejos emerge como crucial por la larga relación con la enfermedad y con los enfermos en la familia. No obstante, este papel permanece poco explorado, en particular, en enfermedades genéticas, como la paramiloidosis. Este estudio cualitativo exploratorio analiza el papel de los más viejos, en familias con paramiloidosis, en la promoción de la salud de los más jóvenes. Se adoptó la técnica de los incidentes críticos, aplicada por entrevista semiestructurada. El estudio involucró a 18 participantes que relataron 76 incidentes críticos. Las entrevistas fueron grabadas y sometidas a un análisis de contenido. Los principales resultados sugieren los siguientes papeles de los más viejos, junto a los más jóvenes: modelar (comportamientos), animar, informar y apoyar. Las generaciones más viejas pueden estar involucradas por los profesionales de salud como agentes activos en el apoyo a los más jóvenes en familias con paramiloidosis.

Promoción de la Salud; Enfermedades Genéticas Congénitas; Amiloidosis Familiar; Relaciones Familiares
Recebido em 09/Nov/2015

Versão final reapresentada em 03/Jul/2016 Aprovado em 20/Jul/2016 